Review Article

\title{
Medicinal Properties of Aragvadha (Cassia fistula Linn.)
}

\author{
Pavan Kumar. S*, Murali Krishna $\mathrm{C}^{1}$, Bhuvenesh Kumar Sharma ${ }^{1}$, \\ Rajashekharan $\mathrm{R}^{2}$, Prasad G.P $\mathrm{P}^{3}$, Narayana. A
}

1. Research Officer (Ayurveda), 2. Research Officer (Siddha), 3. Assistant Director, 4.Director, NIIMH, Hyderabad

\begin{abstract}
Ayurveda, the Indian system of medicine, practiced since a long time for leading a disease free life. It relies mainly upon the medicinal plants for the management of various ailments. Aragvadha (Cassia fistula Linn.) is a plant drug which is being used in the medicines in Ayurveda, Unani and Siddha systems of medicine since ages. It has good ornamental and medicinal value. It is mentioned to be useful in the diseases like fever, skin disorders, rheumatic disorders etc and acts as anti-inflammatory, anti-pyretic etc. The pharmacological potential of Cassia fistula Linn is enumerated with the modern day researches.
\end{abstract}

Key words: Pharmacology, Aragvadha, Cassia fistula.

\section{Introduction:}

Ayurveda, the Indian system of medicine, practiced since a long time for leading a disease free life. It relies mainly upon the medicinal plants for the management of various ailments. There are a wide range of the medicinal plants described in Ayurveda. Some of these plants are extinct and some are still unidentified. A few plants are still used as the richest source of medicines since the ages. Aragvadha (Cassia fistula Linn.) is one such plant drug which is being used in the medicines in Ayurveda, Unani and Siddha systems of medicine since ages. These plants are often cultivated for its beautiful flowers in the gardens. Apart from the ornamental value this drug proves to be one of the plants having good medicinal value.

*Corresponding author:

Senior Research Fellow (Ph.D) (Ayurveda), National institute of Indian Medical

Heritage, Osmania Medical College

building, Putlibowli, Hyderabad.

Ph.No: +91-9493410914

E.mail: pavansangu@gmail.com
In this regard medicinal properties of Aragvadha (Cassia fistula Linn.) are being explored to enumerate the pharmacological potential of the drug.

Cassia fistula Linn. (Family: Caesalpiniaceae) is a moderate to medium sized deciduous tree growing up to 9 meters height and having spreading branches. Leaves are $20-40 \mathrm{~cm}$ long paripinnate. Leaflets are large oblong lanceolate, acute or acuminate tip and pubescent beneath with numerous close slender main nerves. Flowers are bright yellow in colour and are found on long slender pendulous racemes. Fruits are pendulous, cylindrical, nearly straight, dark brown or brownish black, smooth, shining, hard, indehiscent. Seeds are many, broadly ovate, smooth, and light brown to dark brown in colour (1).

It is mentioned with the synonyms like Aragvadha, Rajavruksha, Shampaaka, Chaturangula, Arevatha, Vyadhidhaata, Kruthamaala, Suvarnaka, Kamikaara, Deergaphala, Swarnanga, Swarnabhushana etc. in the Ayurvedic texts. It is known as in Amlathas, Sonhali in Hindi and Indian labernum, Pudding 
pipe tree, Purging cassia in English $(1,2,3)$.

\section{Traditional medicinal uses: $(2)$}

In Ayurvedic classics it is mentioned that Aragvadha is sweet and bitter in taste, heavy, cooling and sweet in vipaka. It is useful to reduce various diseases like Fever (Jwara), Skin Diseases (Kushta), Rheumatic Diseases (Amavaata), Cervical Lyrnphadenitis (Gandamaala), Cardiac Diseases (Hrudroga), Worm Infestations (Krimi), Abdominal Pain (Shoola), Abdominal Disorders (Udararoga), Polyuria (Prameha), Dysuria (Mootrakrucha), Bloating of Abdomen (Gulma) etc. It also reduces all the three dosha. It acts as laxative (Mrudurechaka).

The fruit of it is said to be Laxative (Sramsanam), increases taste perception (Ruchya), reduces skin disorders (Kushta), pitha and kapha. This is said to be the best drug for laxation during fevers. And it is also said to be the best for the elimination of doshas of the gastrointestinal tract (kostashuddikaram param).

\section{Phytochemistry: (4) \\ Root bark:}

An important chemical called fistucacidin, a hydroxy athraquinone type compound and its antibacterial effect was reported from the root bark.

\section{Stem Bark and heart wood:}

The bark and the heart wood contain fistucacidin an optically inactive leucoanthracyanidin $3,4,7,8,4$ 'pentahydroxyflavan along with barbaloin and rhein.

N-Butanol extract of the powdered stem bark contained tannins.

The benzene extract yielded lupeol, $\beta$-Sitosterol and hexacosanol.

\section{Leaves:}

Leaves contain anthraquinone derivatives, tannins, free rhein, rhein glycoside, Sennoside-A and Sennoside-B. glycosides.

They also contained kaempferol

\section{Flowers:}

Other compounds isolated were: sitosterol, n-triancontanol, leucopelargonidin and a mixture of flavonoids and glucosides. Ceryl alcohol, kaempferol, rhein and new bianthraquinone glycosides, fistulin isolated from the ethanol extract of the flowers.

\section{Pods:}

An anthraquinone fistulic acid is obtained from the alcoholic extract.

\section{Pharmacological Actions: Anti-Inflammatory:}

Dried fruits of Cassia fistula L. showed anti-inflammatory activity at 500 $\mathrm{mg} / \mathrm{kg}$ dose. 1:1 combination of the dried fruit extracts of Solanum xanthocarpum and Cassia fistula showed synergetic action at $500 \mathrm{mg} / \mathrm{kg}$ showed maximum inhibition of $75 \%$ compared to the $81 \%$ inhibition in diclofenac sodium treated positive control group. (5)

The aqueous extract of the leaves, stem bark, root bark and fruit pulp in a dose of $1 \mathrm{gm} / 100 \mathrm{gm}$ body weight produced significant anti-inflammatory effect on albino rats.

The acqueous extract of the fruit caused an inhibitory effect on the isolated hearts of the frogs and rabbits. At a dose of $80 \mathrm{mg}$ and above, it exhibited stimulant effect on the smooth muscle of rabbit duodenum and guinea pig ileurn in vitro. The extract had a relaxant effect on the dog's intestine in vitro. On isolated rat uterus, the extract had slight stimulant action in dose 25mg- 1 gm (LillyKutty 1965).

\section{Antipyretic and Analgesic activity:}

It has been found to possess significant antipyretic and analgesic properties (Patel et.al. 1965). 


\section{Antibacterial Activity: (6)}

The leaves stem bark and fruit pulp was found to have antibacterial activity, the fruit pulp being the most potent in this respect. Maximum activity is seen against S. aureus, S. albus, B. megathenin, S. flexueri, S. typhui A \& B and 1 gm of this extract was more potent than $100 \mathrm{gm}$ of chloramphenical in vitro. This activity was attributed to the presence of rhein.

Cassia fistula, Terminalia arjuna and Vitex negundo showed significant antibacterial activity against Escherichia coli, Klebsiella aerogenes, Proteus vulgaris, and Pseudomonas aerogenes (gram-negative bacteria) at 1000-5000 ppm (7).

\section{Anti-Fungal Activity:}

The acetone extracts of the root bark and stem bark had anti-fungal activity against $\mathrm{T}$. rubrum and T.megnini. The root bark had the maximum activity $100 \mathrm{mg}$ of it being more potent than 16.tgm of griseofulvin in vitro. The activity might be due to the presence of flavonoids (LillyKutty and Santhakumari 1969).

4-hydroxy benzoic acid hydrate obtained from the extracts of the flower of Cassia fistula (an ethnomedicinal plant) showed antifungal activity against richophyton mentagrophytes (MIC 0.5 $\mathrm{mg} / \mathrm{ml}$ ) and Epidermophyton floccosum (MIC $0.5 \mathrm{mg} / \mathrm{ml}$ ). (8)

\section{Antiviral Activity:}

The alcoholic extracts of the pods and stem bark were found to have antiviral activity. They also possessed hypoglycaemia activity in albino rats.

\section{Skin Diseases:}

The efficacy of the Cassia fistula in skin diseases may be attributed to the presence of anthraquinone derivatives specially chrysopherol.

\section{Hepatoprotective activity:}

Ethanolic leaf extract and fruit extract showed Hepatoprotective activity against diethylnitrosamine and bomobenzene induced hepatotoxicity $(9,10,11,12,13)$.

Pretreatment with C. fistula showed antioxidant and hepatoprotective properties against $\mathrm{CCl} 4$ induced hepatotoxicity. (14)

\section{Anti-ulcer activity:}

The ethanol leaf extract (ELE) of

Cassia fistula Linn. (Caesalpinaceae) showed antiulcer activity could be attributed to a decrease in gastric acid secretion, protection of the mucosal barrier and restoration of mucosal secretions, inhibition of free radical generation or prevention of lipid peroxidation, and free radical scavenging or antioxidant properties.(15)

\section{Hypoglycemic activity:}

Catechin isolated from Cassia fistula possesses hypo-glycemic, Glucose oxidizing and insulin mimetic activities and hence it could be used as a drug for treating diabetes.(16)

\section{Anti-fertility:}

Cassia fistula reversibly suppresses fertility in male rats. Withdrawal of extract restored all the altered parameters, including organ weights, fertility, circulatory level of hormones and tissue biochemistry, to control levels after 120 days (17).

Oral administration of aqueous extract of seeds of Cassia fistula to mated female rats from day 1-5 of pregnancy at the doses of 100 and $200 \mathrm{mg} / \mathrm{kg}$ body weight resulted in $57.14 \%$ and $71.43 \%$ prevention of pregnancy, respectively, whereas $100 \%$ pregnancy inhibition was noted at $500 \mathrm{mg} / \mathrm{kg}$ bw (23) 


\section{Larvicidal activity:}

The crude extract of Cassia fistula served as a potential larvicidal, ovicidal and repellent agent against chikungunya vector mosquito $(18,19)$.

\section{Wound healing property:}

Along with the other activities such as antitumor, antioxidant, hypoglycemic, hepatoprotective, antibacterial, hypocholesterolaemic, and antidiabetic activity, the healing potential of $\mathrm{C}$. fistula provides a scientific rationale for the traditional use of this plant in the management of infected dermal wound and can be further investigated as a substitute to treat infected wounds without using synthetic antibiotics.(20)

\section{Antioxidative activity:}

Aqueous extract of Cassia fistula (Linn.) flowers (ACF) has got promising antioxidative activity in alloxan diabetic rats (21).

The antioxidant activities of reproductive parts were higher than those of the vegetative organs, with the pods having highest total phenolic, proanthocyanidin, and flavonoid contents and antioxidant potentials (TEAC $=992$ +/- $0.4 \mathrm{micromol} / \mathrm{g}$ dry weight; FRAP $=$ $811+/-23 \mathrm{micromol} / \mathrm{g}$ dry weight) (22).

\section{Anti-tumour activity:}

Methanolic extract (ME) of $\mathrm{C}$. fistula seed has showed an antitumor activity (24).

\section{Conclusion:}

From the above it can be concluded that the drug Aragvadha (Cassia fistula Linn.) proved to have extensive medicinal value in the treatment of diseases like fever, skin disorders, abdominal disorders etc.

It also has hepato-protective, antitumor, anti-inflammatory, anti-fertility, antibiotic, antifungal, hypoglycemic etc., activities.
Thus it can be concluded that the drug if explored can become a single drug remedy for many pathological conditions in a cost effective and easily available way.

\section{References:}

1. Kirtikar KR, Basu BD. Indian Medicinal Plants. Vol-2, Second Edition. Dehradun; M/s Bishne Singh Mahendra Pal Singh, 1975; 856-859

2. Srikantha Murthy KR. Bhavaprakash nighantu of Bhavamishra. Vol-1. Varanasi. Chowkhamba Krishnadas Academy; 2004; 182

3. Nadkarni AK. Indian Materia Medica. Vol-1. Third edition. Bombay. Popular Prakashan; 1976; 285-286

4. Anonymous. Phytochemical investigations of Certain Medicinal Plants used in Ayurveda. New Delhi. CCRAS; 1990; 27-29

5. Anwikar S, Bhitre M; Study of the synergistic anti-inflammatory activity of Solanum xanthocarpum Schrad and Wendl and Cassia fistula Linn; Int J Ayurveda Res. 2010 Jul;1(3):167-71.

6. Bussmann RW et.al; Minimum inhibitory concentrations of medicinal plants used in Northern Peru as antibacterial remedies; J Ethnopharmacol. $2010 \quad$ Oct 28;132(1):101-8. Epub 2010 Aug 1.

7. Perumal Samy $R$, Ignacimuthu $S$, Sen A; Screening of 34 Indian medicinal plants for antibacterial properties; J Ethnopharmacol. 1998 Sep;62(2):17382.

8. Duraipandiyan $\mathrm{V}$, Ignacimuthu $\mathrm{S}$. Antibacterial and antifungal activity of Cassia fistula L.: an ethnomedicinal plant. J Ethnopharmacol. 2007 Jul 25;112(3):590-4. Epub 2007 Apr 24.

9. Pradeep K, Raj Mohan CV, Gobianand K, Karthikeyan S; Protective effect of Cassia fistula Linn. on diethylnitrosamine induced hepatocellular damage and oxidative stress in ethanol pretreated rats; Biol 
Res. 2010 00;43(1):113-125. Epub 2010 May 7.

10. Biol Res. 2010 00;43(1):113-125. Epub 2010 May 7; Protective effect of Cassia fistula fruit extract against bromobenzene-induced liver injury in mice; Hum Exp Toxicol. 2010 Oct 7. [Epub ahead of print]

11. Pradeep K, Mohan CV, Gobianand K, Karthikeyan S; Effect of Cassia fistula Linn. leaf extract on diethylnitrosamine induced hepatic injury in rats; Chem Biol Interact. 2007 Apr 5;167(1):12-8. Epub 2006 Dec 30.

12. Bhakta T, Banerjee S, Mandal SC, Maity TK, Saha BP, Pal M; Hepatoprotective activity of Cassia fistula leaf extract; Phytomedicine. 2001 May;8(3):220-4.

13. Bhakta T, Mukherjee PK, Mukherjee K, Banerjee S, Mandal SC, Maity TK, Pal M, Saha BP; Evaluation of hepatoprotective activity of Cassia fistula leaf extract; J Ethnopharmacol. 1999 Sep;66(3):277-82.

14. Pradeep K, Mohan CV, Anand KG, Karthikeyan S; Effect of pretreatment of Cassia fistula Linn. leaf extract against subacute $\mathrm{CCl} 4$ induced hepatotoxicity in rats; Indian $\mathrm{J}$ Exp Biol. 2005 Jun;43(6):526-30.

15. Karthikeyan S, Gobianand K; Antiulcer activity of ethanol leaf extract of Cassia fistula; Pharm Biol. 2010 Aug;48(8):869-77.

16. Daisy P, Balasubramanian K, Rajalakshmi M, Eliza J, Selvaraj J.; Insulin mimetic impact of Catechin isolated from Cassia fistula on the glucose oxidation and molecular mechanisms of glucose uptake on Streptozotocin-induced diabetic Wistar rats; Phytomedicine. 2010 Jan;17(1):28-36.

17. Chauhan A, Agarwal M; Evaluating the antifertility potential of an aqueous extract from Cassia fistula seeds in male rats; Fertil Steril. 2010 Mar 15;93(5):1706-10. Epub 2009 Oct 12.

18. Govindarajan M; Bioefficacy of Cassia fistula Linn. (Leguminosae) leaf extract against chikungunya vector, Aedes aegypti (Diptera: Culicidae); Eur Rev Med Pharmacol Sci. 2009 Mar-Apr;13(2):99-103.

19. Govindarajan M, Jebanesan A, Pushpanathan T.Larvicidal and ovicidal activity of Cassia fistula Linn. leaf extract against filarial and malarial vector mosquitoes.Parasitol Res. 2008 Jan;102(2):289-92. Epub 2007 Nov 8.

20. Senthil Kumar M, Sripriya R, Vijaya Raghavan H, Sehgal PK; Wound healing potential of Cassia fistula on infected albino rat model; J Surg Res. 2006 Apr;131(2):283-9. Epub 2005 Oct 20.

21. Manonmani G, Bhavapriya V, Kalpana S, Govindasamy S, Apparanantham T; Antioxidant activity of Cassia fistula (Linn.) flowers in alloxan induced diabetic rats; J Ethnopharmacol. 2005 Feb 10;97(1):39-42. Epub 2004 Dec 19.

22. Luximon-Ramma A, Bahorun $\mathrm{T}$, Soobrattee MA, Aruoma OI; Antioxidant activities of phenolic, proanthocyanidin, and flavonoid components in extracts of Cassia fistula; J Agric Food Chem. 2002 Aug 28;50(18):5042-7.

23. Yadav R, Jain GC; Antifertility effect of aqueous extract of seeds of Cassia fistula in female rats; Adv Contracept. 1999;15(4):293-301.

24. Gupta M, Mazumder UK, Rath N, Mukhopadhyay DK; Antitumor activity of methanolic extract of Cassia fistula L. seed against Ehrlich ascites carcinoma; J Ethnopharmacol. 2000 Sep; 72 (1-2):151-6. 